\title{
Ultra-som terapêutico na cicatrização tecidual
}

\author{
Therapeutic ultrasound in the tissue healing \\ Débora Cristina Olsson ${ }^{\mathrm{I}}$ Vera Maria Villamil Martins ${ }^{\mathrm{II}}$ Ney Luis Pippi ${ }^{\mathrm{II}}$ \\ Alexandre Mazzanti ${ }^{\mathrm{II}}$ Guilherme Kanciukaitis Tognoli ${ }^{\mathrm{I}}$
}

\section{- REVISÃO BIBLIOGRÁFICA -}

\section{RESUMO}

Visando a minimizar o período de tratamento cicatricial em diversos tecidos, buscam-se alternativas à terapia convencional que colaborem com o processo reparativo criando um microambiente ideal para sua ocorrência. Dentre os inúmeros benefícios das técnicas aplicáveis à medicina regenerativa, o ultra-som terapêutico (UST) é prática adjuvante cada vez mais freqüente. Os modelos experimentais de terapia sonora em animais têm propiciado informações relevantes para o tratamento de vários tipos de lesões; todavia, apesar de serem muito utilizados, ainda existem controvérsias em relação aos seus potenciaia biológicos de acordo com a modalidade e a dosimetria indicadas para cada caso. Os efeitos biofísicos do ultra-som (US) sobre o reparo tecidual são pouco compreendidos, sendo seu uso muitas vezes negligenciado ou fundamentado na experiência prática, o que resulta em procedimentos errôneos. O objetivo desta revisão bibliográfica é apresentar informações sobre o UST, relatar a existência de riscos de danos celulares decorrentes da inadequada aplicação e revelar a importância de seus mecanismos de ação nos tecidos, tanto no sentido físico, como nos seus aspectos biológicos.

Palavras-chave: ultra-som terapêutico, efeitos biofísicos, cicatrização, tecidos.

\section{ABSTRACT}

Aiming to minimize the cicatricial treatment period, alternatives have been searched to conventional therapy, among which the therapeutic ultrasound is a practice more and more frequent. However, despite of being used in the treatment of various lesions types, there are still controversies related to its real therapeutical value and the indicated dosimetry for each case. The ultrasound effect on the tissue repair is little understood, and its use is seldom based on the practical experience, what sometimes results in wrong procedures. This review has the objective to show the therapeutic ultrasound information and to reveal the importance of its mechanisms in the tissues in the physical and biological aspects.

Key words: ultrasound, therapy, bioeffects, healing.

\section{INTRODUÇÃO}

A evolução do processo cicatricial envolve uma série de eventos que representam uma tentativa de restabelecer a estrutura anatômica e a função normal da região afetada. Neste fenômeno, vários fatores sistêmicos e locais estão envolvidos e o desequilíbrio ou ausência de elementos, principalmente a formação de colágeno, podem comprometer o resultado final da regeneração (COELHO et al., 2002). Dentre os fatores sistêmicos, destacam-se a idade do paciente e a concentração sérica de proteínas (STASHAK, 1991; WITTE \& BARBUL, 1997) e, entre os fatores locais, a sua região anatômica da ferida, a presença de infecção e a desvitalização dos tecidos (SANTOS, 2000).

\footnotetext{
IPrograma de Pós-graduação em Medicina Veterinária, Departamento de Clínica de Pequenos Animais, Laboratório de Cirurgia Experimental, Universidade Federal de Santa Maria (UFSM). Endereço para correspondência: Rua Adriano Chaves, 199, apt ${ }^{\circ} 101$, 97105-010, Camobi, Santa Maria, RS, Brasil. E-mail oldeby@yahoo.com.br.

IIDepartamento de Clínica e Patologia, Centro de Ciências Agroveterinárias, Universidade do Estado de Santa Catarina (CAV/ UDESC), Lages, SC, Brasil.

IIIDepartamento de Clínica de Pequenos Animais, UFSM, Santa Maria, RS, Brasil.
} 
Nos animais, a cicatrização pode ser lenta em decorrência de doenças ou debilitação fisiológica (FOSSUM et al., 2002) e do estado nutricional, uma vez que as proteínas são fundamentais para todos os aspectos da reparação tecidual, tal qual a síntese de colágeno, a proliferação epidérmica e a neovascularização (STARKEY, 2001). A hipoproteinemia, além de prolongar o tempo de cicatrização, acentua a imunossupressão (JOHNSTON, 1990), diminuindo a oxigenação e a perfusão tissular, que são consideradas essenciais para a manutenção da integridade e para o sucesso na reparação. A isquemia causada por tensão em áreas de edema ou sutura apertada em cirurgias altera o metabolismo celular, aumentando o tempo de cicatrização e o risco de infecção (YAMADA, 2003).

A forma de tratamento para as lesões depende de uma avaliação acurada da lesão, identificando-se o estágio do processo cicatricial. Embora haja muitas opções para auxiliar no processo reparativo, esses fármacos nem sempre são eficazes e muitas vezes o custo do tratamento os torna inviáveis (HUSSNI et al., 2004). Dentre os recursos disponíveis para o tratamento de lesões, a utilização de terapias alternativas não invasivas na cicatrização tecidual têm se mostrado de fundamental importância para o estímulo da preservação das funções fisiológicas, da estrutura celular e para a melhora na qualidade do tecido neoformado (YAMADA, 2003).

Dentre os tratamentos não-invasivos, a energia ultra-sônica é um dos procedimentos físicos adjuvantes mais utilizados em fisioterapia e medicina regenerativa para o tratamento de diversas doenças. Seus efeitos terapêuticos têm se mostrado benéficos no tratamento de uma grande variedade de condições, como cicatrização de úlceras (DYSON \& SUCKLING, 1978), estímulo à neovascularização em tecidos isquêmicos (HOGAN et al., 1982), integração de enxertos de pele total (AMANCIO et al., 2006), consolidação de fraturas e pseudo-artroses (DUARTE \& XAVIER, 1983; CARVALHO \& CLIQUET JR, 2003) e também na cicatrização tendinosa (SILVEIRA, 2003). O UST induz mudanças fisiológicas como ativação de fibroblasto, colágeno e diminuição de células inflamatórias por aceleração do metabolismo celular (OLSSON et al., 2006) e, quando aplicado de maneira adequada, pode reduzir a dor (STEISS \& ADAMS, 1999).

O objetivo desta revisão bibliográfica é apresentar informações sobre o UST, relatar a existência de riscos de lesões celulares decorrentes da inadequada aplicação e revelar a importância dos efeitos físicos de acordo com a modalidade, intensidade e freqüência das ondas sonoras transferidas aos tecidos em processos cicatriciais.
Ultra-som terapêutico

O US é uma modalidade de energia sonora longitudinal, de penetração profunda, que, ao ser transmitida aos tecidos biológicos, é capaz de produzir alterações celulares por efeitos mecânicos. A transmissão ocorre pelas vibrações das moléculas do meio através do qual a onda se propaga. Este meio irradiado oscila ritmicamente com a freqüência do gerador ultra-sônico por efeito piezoelétrico, ao comprimir e expandir a matéria (GUIRRO et al., 1995; ARNAULD-TAYLOR, 1999). Para que haja propagação dessas ondas ultra-sônicas é necessário que o meio tenha propriedades elásticas. O movimento de um corpo vibrando é transmitido às moléculas adjacentes, as quais, antes de retornarem à posição de equilíbrio, transmitem esse movimento para as moléculas que estão ao redor (MARTINES et al., 2000).

A energia sonora terapêutica é gerada por um transdutor que transforma a energia inicial elétrica em energia mecânica. Antes que o US possa ser aplicado, o aparelho deve ser ajustado e a saída de energia estabelecida. $\mathrm{O}$ contato entre o transdutor e a pele deve ser adequado para que não haja perda de ondas, já que o ar é um péssimo condutor (LEHMANN \& DeLATEUR, 1994). Vários métodos estão disponíveis para a aplicação do UST, entre eles o direto ou deslizamento, o subaquático, o balão, o refletor, o funil, o paravertebral reflexo e o redutor de cabeçote. Para a escolha do método direto é necessária a utilização de um meio acoplador, podendo ser vaselina, óleo ou gel (MACHADO, 1991; PAULA, 1994).

Em média, o tempo de aplicação do UST é de quatro a dez minutos por área, sendo que, para grandes superfícies, o segmento é dividido em três ou quatro partes iguais, e aplica-se o mesmo tempo por área (MACHADO, 1991; LEHMANN \& DeLATEUR, 1994). Esta aplicação pode ser de forma estacionária ou não, sendo que a primeira pode levar a uma elevação muito rápida da temperatura, ocasionando queimaduras. O aumento da intensidade não pode compensar a diminuição do tempo de tratamento, porque o efeito produzido pelas duas variedades é diferente. Aumentar a intensidade pode elevar excessivamente a temperatura do tecido, e conseqüentemente ter efeitos indesejáveis, como desvitalização da região irradiada (PAULA, 1994).

À medida que o US atravessa o tecido, parte da energia é refletida pelas estruturas que se encontram em sua trajetória, o que caracteriza espalhamento, e parte da energia é absorvida pelo próprio meio, levando a um aquecimento local ou absorção. A atenuação ou perda da energia pelo feixe sonoro deve-se a esses dois mecanismos, em que a absorção representa 60- 
$80 \%$ da perda da energia (TER HAAR, 1999). Nos tecidos biológicos, a atenuação deve-se principalmente aos mecanismos de absorção pelos quais a energia mecânica das ondas ultra-sônicas é convertida em calor e reflexão da energia ultra-sonográfica nas interfaces teciduais (TER HAAR, 1978; BAKER et al., 2001).

As ondas ultra-sônicas podem ser aplicadas por dois métodos conhecidos como contínuo e pulsado, sendo que a diferença entre os modos está na interrupção da propagação das ondas. No contínuo, a voltagem através do transdutor do US deve ser aplicada continuamente, e seus ciclos de freqüência são acima de $100 \%$, durante todo o período de tratamento. No pulsado, a voltagem é aplicada em rajadas (TER HAAR, 1999), com ciclos de freqüência menores que $100 \%$ (GUIRRO \& SANTOS, 1997). Assim, o efeito térmico é menos pronunciado e o efeito mecânico é superior, possibilitando a abertura de campos de tratamentos onde não é desejável o efeito predominantemente térmico, como exemplo, o tratamento para a dor (KITCHEN \& PARTRIDGE, 1990).

A intensidade da radiação ultra-sônica é fator essencial para o sucesso de qualquer terapia, bem como o seu tempo de aplicação. A quantidade de energia total depositada sobre um determinado tecido biológico é o produto da intensidade com o tempo de aplicação (GUIRRO \& SANTOS, 1997; FERNANDES et al., 2003), que, convencionalmente, na terapia ultra-sônica, varia entre $0,01 \mathrm{a}^{3 \mathrm{~W} \mathrm{~cm}} \mathrm{c}^{-2}$ (TER HAAR, 1996) e emprega uma freqüência de 1 a $3 \mathrm{MHz}$,com ciclos de ondas que variam de 20 a 100\% (GUIRRO \& SANTOS, 1997). Não existem dados científicos ou clínicos quantitativos que indiquem a utilização de níveis de US acima de $1 \mathrm{~W} \mathrm{~cm}^{-2}$ para promover um efeito significativo em tecidos lesionados. Utilizam-se valores de intensidade de $0,5 \mathrm{~W}$ $\mathrm{cm}^{-2}$ ou inferiores para que sejam atingidas as maiores velocidades de cicatrização em tecidos como pele, tendões e ossos, em qualquer espécie (LEHMANN \& DeLAUTEUR, 1994; LOW \& REED, 2001). Há evidências de que níveis de UST superiores a 1,5W $\mathrm{cm}^{-2}$ exerçam um efeito adverso nos tecidos em processo de reparação. Efeitos térmicos significativos podem ser obtidos usando intensidade entre 0,5 e $1 \mathrm{~W} \mathrm{~cm}^{-2}$ (KITCHEN \& BAZIN, 1996).

Independentemente do tipo de mecanismo de interação agindo no tecido biológico estudado, o objetivo principal desta terapia é estabelecer limiares para a intensidade ultra-sônica, abaixo dos quais não ocorrem efeitos lesivos (KORNOWSKI et al., 1994).

Efeitos térmicos, mecânicos e biológicos do ultra-som Em conseqüência das vibrações longitudinais provocadas pelo UST, um gradiente de pressão é desenvolvido nas células individuais. Como resultado desta variação de pressão negativa, elementos da célula são obrigados a se moverem através de um efeito de micromassagem. Este efeito aumenta o metabolismo celular, o fluxo sangüíneo, o suprimento de oxigênio e, até mesmo, a temperatura local (KITCHEN \& PARTRIDGE, 1990), ou seja, age como um catalisador físico, acelerando as trocas celulares (MACHADO, 1991).

O calor pode ser considerado uma forma de energia intercambiável com outras formas de energia, como a elétrica e a mecânica. Quando um corpo é aquecido, a elevação na temperatura leva ao aumento da movimentação das moléculas presentes no corpo considerado. Quando uma forma de energia é convertida em outra, o processo não é completamente eficiente e somente parte da energia é convertida em calor dentro do tecido. A quantidade de absorção depende da natureza tissular, do grau de vascularização e da freqüência gerada. Tecidos com elevados conteúdos protéicos absorvem mais rapidamente do que aqueles com conteúdo elevado de gordura, e, quanto maior a freqüência, maior a absorção (PARTRIDGE, 1987; KITCHEN \& BAZIN, 1996).

Um efeito térmico biologicamente significativo pode ser obtido se a temperatura tecidual for elevada para 40 ou $45^{\circ} \mathrm{C}$, durante um mínimo de cinco minutos (Tabela 1). O UST causa pouca elevação de temperatura nos tecidos superficiais e tem maior profundidade de penetração na musculatura e em outros tecidos moles do que a diatermia de ondas curtas e microondas (RODRIGUES \& GUIMARÃES, 1998). A vantagem dessa forma de atividade térmica em relação a outras de uso comum é o calor dirigido (ARNOULD-TAYLOR, 1999). Os efeitos térmicos dessa categoria incluem alívio da dor, da inflamação aguda ou crônica, inibição dos espasmos musculares, aumentando ainda a extensibilidade do colágeno (BASFORD, 1998; STEISS \& ADAMS, 1999). Esses efeitos são determinados por diversos fatores, como o tempo de irradiação local; a técnica de aplicação (estacionária ou móvel); as dimensões do corpo aquecido e a presença de superfícies refletoras proximal ou distal ao tecido de interesse (WILLIAMS, 1983). A intensidade da radiação ultra-sônica é fator essencial para o sucesso de qualquer terapia (GUIRRO \& SANTOS, 1997).

Os efeitos físicos não-térmicos desejáveis causam o aumento da permeabilidade celular, da síntese protéica, do fluxo de íons de cálcio e da passagem de metabólitos através da membrana celular, o que contribui de forma positiva na reparação tecidual (LOW \& REED, 2001). As vibrações acústicas induzem 
Tabela 1 - Efeitos atribuídos ao ultra-som terapêutico na freqüência entre 0,75 a $3 \mathrm{MHz}$ sobre estruturas da membrana celular e seus respectivos resultados biológicos.

\begin{tabular}{ll}
\hline Tipos de efeito & Resultados \\
\hline & Aumento da extensibilidade tecidual \\
& Aumento do fluxo sangüíneo \\
& Modulação da dor \\
Modulação da resposta inflamatória & Redução da rigidez articular \\
& Redução de espasmos musculares \\
& Cavitação \\
Microderrames acústicos & Em combinação, a cavitação e os microderrames acústicos podem resultar em estimulação da atividade \\
Atérmicos & fibroblástica, aumento do fluxo sangüíneo, regeneração tecidual e cicatrização óssea. \\
\hline
\end{tabular}

Fonte: SPEDD, (2001).

mudanças celulares, alterando o gradiente de concentração das moléculas e íons (cálcio e potássio), estimulando a atividade celular caso esta vibração ocorra nos limites da membrana com o líquido circunjacente (TER HAAR, 1999). Esse fenômeno pode resultar num aumento da síntese de proteínas e secreção de mastócitos, ocorrendo alteração na mobilidade dos fibroblastos, dentre outros (TER HAAR, 1996).

Existem muitas situações em que o US produz efeitos físicos, sem envolvimento de uma temperatura significativa. Supõe-se que alguns mecanismos físicos estão envolvidos na produção destes efeitos atérmicos, como cavitação, correntes acústicas e ondas estacionárias (LOW \& REED, 2001; TAYLOR et al., 2004). O termo atérmico é freqüentemente utilizado, significando um tratamento que não resulta em percepção consciente por parte do paciente de qualquer sensação térmica. Os tratamentos envolvem a produção de baixos níveis de calor, que possivelmente sejam convertidos em alterações químicas no interior da célula (PARTRIDGE, 1987; RODRIGUES \& GUIMARÃES, 1998).

A produção de ondas ultra-sônicas é um fenômeno físico baseado no processo de criar, aumentar e implodir cavidades de vapor e gases em um líquido, denominado cavitação, promovendo efeitos de ativação em reações químicas (YOUNG, 1988). Durante a etapa de compressão, a pressão é positiva, enquanto que a expansão resulta em vácuo, chamado de pressão negativa, constituindo-se em um ciclo de compressão-expansão que gera as cavidades. A origem da cavitação se deve ao fato de que, durante a expansão, os gases adsorvidos nos líquidos ao redor da cavidade ou na interface evaporam-se, resultando na expansão da cavidade, podendo provocar a formação de bolhas ou cavidades micrométricas nos líquidos contendo gás (MARTINES et al., 2000). Dependendo da amplitude de pressão da energia, as bolhas resultantes podem ser úteis, ou perigosas. Amplitudes de baixa pressão resultam na formação de bolhas que vibram num certo grau, sendo então produzidas alterações reversíveis na permeabilidade das membranas celulares nas proximidades onde ocorre o evento cavitacional (MORTIMER \& DYSON, 1988). Se for evitado um campo de ondas estacionárias e se forem utilizadas baixas intensidades durante a terapia, será improvável a ocorrência desta cavitação temporária (YOUNG, 1988).

Nos efeitos mecânicos, térmicos e químicos do US, o modo de reação de órgãos isolados e também do organismo como um todo deve ser considerado. A ação biológica é determinada pela interação de diversos fatores, entre eles a sedação, a analgesia, o relaxamento muscular, a hiperemia, a fibrinólise, o aumento da permeabilidade de membranas e o aumento da regeneração tecidual (MACHADO, 1991).

Mecanismos e interação ultra-sônica com tecidos biológicos

Apesar das controvérsias existentes sobre a aceleração da cicatrização (DYSON, 1990), o US tem sido usado com muita freqüência há mais de 40 anos para o tratamento de desordens musculoesqueléticas como tendinites, sinovites, tenosinovites, epicondilites, bursites e osteoartrites (KLAIMAN et al., 1998). Porém, revisões sistemáticas têm repetidamente concluído que não há evidências suficientes para suportar os benefícios dos efeitos do US nas doses freqüentemente utilizadas nas clínicas (WARDEN, 2003).

A ação do US sobre os tecidos depende grandemente da intensidade empregada, e por isso a

Ciência Rural, v.38, n.4, jul, 2008. 
calibração inadequada pode levar à ineficiência do tratamento ou a produzir novas lesões (GUIRRO \& SANTOS, 1997). Experimentos demonstraram que a interação do US com os tecidos biológicos pode ser benéfica mesmo em processos cicatriciais tardios, melhorando as propriedades mecânicas dos tecidos; porém, se os efeitos acústicos forem mantidos sobre a estrutura tecidual por tempo prolongado, podem provocar desagregação das estruturas e retardo da cicatrização (MAXWELL, 1995). De modo geral, considera-se que a ação terapêutica é resultante dos efeitos térmicos (diatermia) e atérmicos (mecânicos ou biológicos) utilizados no tecido a ser tratado (LOW \& REED, 2001), como mostrado na tabela 1. A terapia pode agir como um estímulo para as células envolvidas no processo de reparo, particularmente na fase inflamatória (no tempo de tratamento e na freqüência de sessões) (FERNANDES et al., 2003). Em intensidades terapêuticas, a energia mecânica não chega a lesar as membranas celulares, mas acelera o intercâmbio entre as células (RODRIGUES \& GUIMARÃES, 1998).

O US contínuo pode aumentar o fluxo sangüíneo por algum tempo após o tratamento; no entanto, esses dados ainda são controversos, pois podem alterar organelas celulares e membranas de maneira reversível ou irreversível, dependendo de sua magnitude (STARKEY, 2001; TAYLOR et al., 2004). O microfluxo pode ter seu valor terapêutico, uma vez que sua ação facilita a difusão através de membranas e, dependendo do tipo de célula, a alteração iônica produzida pode desenvolver alterações na motilidade, síntese ou secreção celular, que podem acelerar o processo de reparo (OKUNO et al., 1986; DYSON, 1987). Segundo BARONE (1989) e DRAPER et al. (1993), o uso do US no passado era indicado com mais freqüência para tratar lesões dos tecidos moles, pois, através dos seus efeitos térmicos e mecânicos, causa alterações biológicas nos tecidos que favorecem a cicatrização de lesões (DYSON, 1987). Os músculos lesados nas suas fibras por incisões com o bisturi regeneram mais precocemente quando se lhes aplica energia ultrasônica pulsada (BASSOLI, 2001). KRISTIANSEN et al. (1997) observaram que, ao serem transmitidas para o interior do corpo, as ondas promovem microdeformações na região óssea estimulada e são capazes de gerar estímulos para acelerar ou iniciar o processo osteogênico.

O sistema circulatório tem a peculiaridade única de interagir com esse tipo de energia, pois apresenta partículas em movimento e vasomotricidade baseada num controle neuro-humoral, o que modifica a dissipação e absorção do feixe sonoro (KORNOWSKI et al., 1994). Respostas como alteração da coagulação (KORNOWSKI et al., 1994; VAEZY et al., 1998) e fibrinólise (HOGAN et al., 1982), bem como estímulo angiogênico, já têm sido descritos em situações específicas e controladas de emprego sonoro (VAEZY et al., 1999). Esta forma de energia é capaz de alcançar grandes profundidades (Tabela 2); entretanto, sabe-se que estruturas nobres e delicadas encontram-se no trajeto do feixe ultra-sônico e estão sujeitas à sua ação (HYNYNEN et al., 1996). LEHMANN et al. (1967) demonstraram efeitos do US na modalidade de aquecimento profundo dos tecidos, irradiando músculos de homens voluntários com intensidade entre 1 e $1,5 \mathrm{~W} \mathrm{~cm} \mathrm{~cm}^{-2}$. O estudo indicou que cinco a dez minutos são suficientes para produzir aquecimento muscular adequado sem danificar os tecidos adjacentes. MENEZES et al. (1999) irradiaram UST em lesão muscular de coelhos com modo de onda pulsada, razão 1:5, freqüência de $1 \mathrm{MHz}$ e intensidade de $0,5 \mathrm{~W} \mathrm{~cm}^{-2}$ por cinco minutos, durante dez dias consecutivos. Os

Tabela 2 - Valores de profundidade atingida pelo ultra-som terapêutico, com freqüências de 1 e 3 MHz em diferentes tecidos, no ar e na água (em mm).

\begin{tabular}{lcc}
\hline & Profundidade média em diversos meios (em mm) & ----------Freqüência---------- \\
\hline Meio & $1 \mathrm{MHz}(\mathrm{mm})$ & $3 \mathrm{MHz}(\mathrm{mm})$ \\
Tecido ósseo & $2,1 \mathrm{~mm}$ & - \\
Pele & $11,1 \mathrm{~mm}$ & $4 \mathrm{~mm}$ \\
Cartilagem & $6 \mathrm{~mm}$ & $2 \mathrm{~mm}$ \\
Ar & $2,5 \mathrm{~mm}$ & $0,8 \mathrm{~mm}$ \\
Tecido tendinoso & $6,2 \mathrm{~mm}$ & $2 \mathrm{~mm}$ \\
Tecido muscular esquelético (fibras em ângulo reto com o feixe sonoro) & $9 \mathrm{~mm}$ & $3 \mathrm{~mm}$ \\
Tecido muscular esquelético (fibras paralelas ao feixe sonoro) & $24,6 \mathrm{~mm}$ & $8 \mathrm{~mm}$ \\
Tecido adiposo & $50 \mathrm{~mm}$ & $16,5 \mathrm{~mm}$ \\
Água & $115.000,0 \mathrm{~mm}$ & $3.833,3 \mathrm{~mm}$ \\
\hline
\end{tabular}

Fonte: HOOGLAND (1986). 
músculos tratados apresentaram diferença significativa na carga muscular e na fase de deformação elástica. Os pesquisadores concluem que a aplicação do UST pode melhorar a qualidade da reparação da lesão muscular aguda.

YOUNG \& DYSON (1990) analisaram os efeitos mecânicos do UST pulsátil, na freqüência de 0,75 ou $3 \mathrm{MHz}$ e intensidade de $0,1 \mathrm{~W} \mathrm{~cm}^{-2}$, por cinco dias, em lesões experimentais de pele em ratos. No grupo estimulado, foi encontrada maior quantidade de tecido de granulação, leucócitos, macrófagos e fibroblastos, sugerindo que o UST pode ser usado para acelerar o processo inflamatório e a proliferação celular durante a cicatrização. GUIRRO et al. (1995) também investigaram os efeitos da energia ultra-sônica pulsátil sobre a cicatrização da parede abdominal de ratos com radiação na intensidade de $16 \mathrm{~mW} \mathrm{~cm}^{-2}$ e notaram diminuição no tempo do processo inflamatório, presença precoce de neoformação de vasos, fibroblastos jovens e maduros e aumento da resistência tênsil. Segundo os autores, o US pode abreviar a cicatrização da parede abdominal de animais submetidos à laparotomia. No entanto, em um estudo realizado por ALVES (1988) sobre os efeitos benéficos das ondas sonoras no tratamento de queimaduras de terceiro grau em ratos, não foram observados efeitos estimulantes do UST no modo contínuo, na intensidade de $0,3 \mathrm{~W} \mathrm{~cm}^{-2}$, e no modo pulsátil, na intensidade de $0,25 \mathrm{~W} \mathrm{~cm}^{-2}$. O autor desconsiderou a aplicação clínica do US para tratar cicatrização de queimaduras.

DUARTE (1983) verificou que o US pulsátil na intensidade de 49,6 ou $57 \mathrm{~mW} \mathrm{~cm}^{-2}$ não apresentava efeitos térmicos em fíbulas e fêmures de coelhos submetidos à osteotomia. RAWOOL et al. (2003) utilizaram o mesmo modo de aplicação com intensidade de $30 \mathrm{~mW} \mathrm{~cm}^{-2}$ em osteotomia ulnar em cães e observaram aumento do fluxo sangüíneo no local da fratura e formação exuberante de calo ósseo em torno do foco lesionado, sugerindo que o mecanismo de ação da estimulação ultra-sônica de baixa intensidade no tecido ósseo deve-se à piezoeletricidade. Ainda, na espécie canina, SOUZA (2003) realizou uma investigação clínica e radiográfica dos efeitos do US pulsado com intensidade de $30 \mathrm{~mW} \mathrm{~cm}^{-2}$ como tratamento adjuvante na consolidação óssea de rádio, ulna, fêmur, tíbia e fíbula, e percebeu uma evolução favorável à formação de calo ósseo, sugerindo que esse método de tratamento pode auxiliar no reparo de fraturas de ossos longos. Essa energia acústica atua como ondas de grande pressão, promovendo forças micromecânicas no osso e em tecidos adjacentes. A fisiologia e a consolidação óssea podem ser influenciadas pela ação de tais forças (MAYR et al.,
2000), promovendo a remodelação haversiana, que ocorre na direção e proporção das forças mecânicas aplicadas, incluindo a estimulação da atividade vascular (PILLA et al., 1990; CARVALHO \& CLIQUET JR, 2003; KORSTJENS et al., 2005).

GRECA et al. (1999) objetivaram conhecer a influência do US de alta freqüência $(0,8$ a $1 \mathrm{MHz})$ em modo contínuo, na dose de $0,5 \mathrm{~W} \mathrm{~cm}^{-2}$, durante três minutos, sobre cicatrização colônica em ratos, e concluíram que o US não influenciou na cicatrização de anastomoses intestinais. NARUSE et al. (2000) investigaram os efeitos do US pulsado em células (ST2) com origem no estroma da medula óssea, 20 minutos após fratura. As células responderam ao estímulo com níveis elevados de RNAs mensageiros de IGF, osteoclastos, e RNAs mensageiros de proteínas ósseas. Os resultados sugerem que ondas sonoras pulsáteis de baixa intensidade aceleram o processo cicatricial de ossos fraturados, induzindo reação anabólica direta de células osteogênicas. Na espécie eqüina, LIPPIELO \& SMALLEY (1991) relataram, após mensuração densitométrica, um aumento de $16 \%$ do índice de reparação óssea em falhas bilaterais do metacarpo, quando submetido ao tratamento com energia de 20 a $30 \mathrm{~mW} \mathrm{~cm}^{-2}$, por 20 minutos, por um período de sete semanas.

SAINI et al. (2002) realizaram estudos sobre os efeitos físicos do US pulsado no tendão de cães em processo de reparo, utilizando uma intensidade de $0,5 \mathrm{~W}$ $\mathrm{cm}^{-2}$ durante dez dias, e concluíram que os tendões tratados apresentaram uma menor adesão, maior formação de fibras e aceleração do reparo tecidual. SILVEIRA (2003) aplicou o protocolo no modo contínuo, com freqüência de $1 \mathrm{MHz}$ e intensidades de $0,5 \mathrm{Wcm}^{-2}$ e $1 \mathrm{~W} \mathrm{~cm} \mathrm{~cm}^{-2}$, por seis minutos, no processo de reparo de tendões. O membro anterior esquerdo foi irradiado com intensidade de $1 \mathrm{~W} \mathrm{~cm}^{-2}$, enquanto que, no membro anterior direito, utilizou-se $0,5 \mathrm{~W} \mathrm{~cm} \mathrm{~cm}^{-2}$. O US terapêutico mostrou-se mais benéfico quando utilizado em intensidades de $1 \mathrm{~W} \mathrm{~cm}^{-2}$, também observando-se ausência de aderências quando os tendões sob esse tratamento foram comparados clinicamente aos membros irradiados com $0,5 \mathrm{~W} \mathrm{~cm}^{-2}$. Porém, histologicamente, não houve diferença nos tendões submetidos aos dois tipos de tratamento. $\mathrm{Na}$ intensidade de $1 \mathrm{~W} \mathrm{~cm} \mathrm{~cm}^{-2}$, estima-se que, após atenuada pelas estruturas intermediárias, o feixe de UST atinja o tecido tendíneo a uma intensidade média de 0,6 a 0,8W $\mathrm{cm}^{-2}$. Essa dosagem seria suficiente para produzir, além de efeitos atérmicos, certo grau de diatermia, provocando analgesia e estimulação dos processos cicatriciais (YOUNG, 1996; KORSTJENS et al., 2004).

Na espécie eqüina, o tratamento das tendinites busca controlar o distúrbio circulatório e a 
intensidade da inflamação, porém os resultados nem sempre são satisfatórios, sendo freqüente a formação de aderências. O tecido cicatricial neoformado é menos resistente que o tendão original, o que predispõe à recurrência da lesão (McILWRAITH, 1994). Entre os recursos avaliados para melhorar a qualidade do tecido cicatricial, os agentes físicos têm sido testados quanto a seus efeitos anti-inflamatórios e como promotores da cicatrização (JACKSON et al., 1991; GUM et al., 1997). FERNANDES et al. (2003) usaram os efeitos do UST em tratamento de tendinite experimental de eqüinos na freqüência de $3 \mathrm{MHz}$ e intensidade de $1 \mathrm{~W} \mathrm{~cm} \mathrm{~cm}^{-2}$ por seis minutos no modo contínuo e na mesma dose e tempo no modo pulsado. A avaliação histológica mostrou neovascularização pronunciada e maior atividade fibroblástica nos grupos tratados nos dois modos. Os autores sugerem que ambas as modalidades são efetivas na redução dos sintomas clínicos da tendinite.

\section{CONCLUSÃO}

Vários experimentos demonstram que o UST é uma forma não invasiva de tratamento na reparação de lesões teciduais, sendo o método pulsátil a modalidade mais escolhida pelos pesquisadores relacionados nesta revisão. Os efeitos benéficos são significativos, sobretudo em baixa intensidade, o que minimiza o risco de lesões teciduais e a formação de cavitações, as quais podem ocorrer com intensidades elevadas associadas ao uso da terapia contínua. O modo de aplicação de ondas pulsadas é um meio apropriado de tratamento ultra-sônico auxiliar no pósoperatório, com a finalidade de diminuir o tempo de recuperação do paciente. Diante de questionamentos ainda existentes quanto ao tempo, à dosimetria e ao modo de aplicação do US em cada espécie animal, sugere-se mais pesquisas sobre essa alternativa terapêutica.

\section{REFERÊNCIAS}

ALVES, J.M. Efeitos da energia ultra-sônica na regeneração de pele de animal com queimadura por calor. 1988. 164f. Dissertação (Mestrado em Engenharia Biomédica) - Escola de Engenharia de São Carlos/ Faculdade de Medicina de Ribeirão Preto/Instituto de Química de São Carlos, Universidade de São Paulo.

AMANCIO, A.C.G. et al. Estimulação ultra-sônica da integração de enxertos de pele total: estudo experimental em coelhos. Acta Ortopedica Brasileira, v.14, n.5, p.276-279, 2006.

ARNOULD-TAYLOR, W. Princípios e prática de fisioterapia. 4.ed. Porto Alegre: Artmed, 1999. 236p.

BAKER, K.G. et al. A review of therapeutic ultrasound: biophysical effects. Physical Therapy, v.81, p.1351-1358, 2001.
BASFORD, J.R. Physical agents. In: DeLISA, J.A.; GANS, B.M. Rehabilitation medicine: principles and practice. Philadelphia: Lippincott-Raven, 1998. p.483-503.

BARONE, J. Topical analgesics: how effective are they? Physical Sports and Medicine, v.17, n.2, p.162-166, 1989.

BASSOLI, D.J. Avaliação dos efeitos do ultra-som pulsado de baixa intensidade na regeneração de músculos esqueléticos com vistas á aplicação em clínica fisioterapêutica. 2001. 186f. Dissertação (Mestrado em Química) - Escola de Engenharia de São Carlos/faculdade de Medicina de Ribeirão Preto- Instituto de Química de São Paulo.

CARVALHO, D.C.L.; CLIQUET JR., A. A ação do ultra-som terapêutico de baixa intensidade em ossos de ratas osteopênicas. Acta Ortopédica Brasileira, v.11, n.1, p.17-24, 2003.

COELHO, M.C.O.C. et al. Biopolímero produzido a partir da cana-de-açúcar para cicatrização cutânea. Acta Cirúrgica Brasileira, v.17, p.11-13, 2002.

DRAPER, D.O. et al. A comparison of temperature rise in human calf muscles following applications of underwater and topical gel ultrasound. Journal Orthopaedic \& Sports Physical Therapy, v.17, p.247-251, 1993.

DUARTE, L.R. The stimulation of bone growth by ultrasound. Archives of Orthopaedic and Traumatic Surgery, v.101, p.153-159, 1983.

DUARTE, L.R.; XAVIER, C.A.M. Estimulação ultrasônica do calo ósseo. Aplicação clínica. Revista Brasileira de Ortopedia, v.18, n.3, p.73-80, 1983.

DYSON, M.; SUCKLING, J. Stimulation of tissue repair by ultrasound: a survey of the mechanisms involved. Physiotherapy, v.64, p.105-108, 1978.

DYSON, M. Mechanisms involved in therapeutic ultrasound, Physiotherapy, v.73, n.3, p.116-120, 1987.

DYSON, M. Role of ultrasound in wound healing. In: KLOTH, L.C.; MILLER, K.H. Wound healing. Philadelphia: F.A. Davis, 1990. p.259-85.

FERNANDES, M.A.L. et al. Efeito do ultra-som terapêutico em tendinite experimental de eqüinos: estudo clínico, ultrasonográfico e histopatológico de dois protocolos. Arquivo Brasileiro de Medicina Veterinária e Zootecnia, v.55, n.1, p.27-34, 2003.

FOSSUM, T.W. et al. Cirurgia de pequenos animais. São Paulo: Roca, 2002. 1335p.

GRECA, F.H. et al. Efeito do ultra-som terapêutico nas anastomoses colônicas. Estudo experimental em ratos. Acta Cirúrgica Brasileira, v.14, n.3, 1999.

GUIRRO, E.C. et al. Efeitos da estimulação ultra-sônica pulsada de baixa intensidade no processo cicatricial: estudo experimental em ratos. Revista Ciência \& Tecnologia, n.8, p.37-47, 1995.

GUIRRO, R.; SANTOS, S.C.B. A realidade da potência acústica emitida pelos equipamentos de ultra-som terapêutico: uma 
revisão. Revista de Fisioterapia da Universidade de São Paulo, v.4, n.2, p.76-82, 1997.

GUM, S.L. et al. Combined ultrasound, electrical stimulation and laser promove collagen syntesis with moderate changes in tendon biomechanics. American Journal of Physical Medicine \& Rehabilitation, v.76, p.288-296, 1997.

HYNYNEN, K. et al. Potential adverse effects of hightintensity focused ultrasound exposure on blood vessels in vivo. Ultrasound in Medicine \& Biology, v.22, n.2, p.193-201, 1996.

HOGAN, R.D. et al. The effects of ultrasound on microvascular hemodynamics in skeletal muscle: effects on arterioles. Ultrasound Medicine Biology, v.8, p.45-55, 1982.

HOOGLAND, R. Manual de terapia ultrasônica. Delft: Manufacturer of Enraf Nonius, 1986. 379p.

HUSSNI, C.A. et al. Second intention skin wound healing in equines under vedaprofen treatment. Archives of Veterinary Science, v.9, n.1, p.87-92, 2004.

JACKSON, B.A. et al. Effect of ultrasound therapy on the repair of Achilles tendon injuries in rats. Medicine Science Sports and Exercise, v.23, p.37-41, 1991.

JOHNSTON, D.E. Wound healing in skin. Veterinary Clinics of North America: Small Animal Practice, v.20, n.1, p.125, 1990.

KITCHEN, S.; BAZIN, S. Eletroterapia de Clayton. 10.ed. São Paulo: Manole, 1996. 350p.

KITCHEN, S.S.; PARTRIDGE, C.J. A review of therapeutic ultrasound: I. Background, physiological effects and hazards. Physiotherapy, v.76, p.593, 1990.

KLAIMAN, M.D. et al. Phonophoresis versus ultrasound in the treatment of common musculoskeletal conditions. Medicine Science \& Exercise, v.30, p.1349-1355, 1998.

KORSTJENS, C.M. et al. Stimulation of bone cell differentiation by low-intensity ultrasound: a histomorphometric in vitro study. Journal Orthopaedic Research, v.22, n.3, p.495-500, 2004.

KORNOWSKI, R. et al. Does external ultrasound accelerate thrombolysis? Results from a rabbit model. Circulation, v.89, p.339-344, 1994.

KRISTIANSEN, T.K. et al. Accelerated healing of distal radial fractures with the use of specific, low-intensity ultrasound. Journal Bone Joint Surgery, v.79, p.961-973, 1997.

LEHMANN, J.F. et al. Therapeutic temperature distribuition produce by ultrasound as modified by dosage and volume of tissue exposed. Archives of Physical Medicine and Rehabilitation, v.48, p.662-666, 1967.

LEHMANN, J.F.; DeLATEUR, B.J. Diatermia e terapia pelo calor e frio superficiais. In: KOTTKE, F.J.et al. Tratado de medicina física e reabilitação. 3.ed. São Paulo: Manole, 1994. Cap.13, p.281-359.

LIPPIELO, L.; SMALLEY, L. Densitometry assessment of equine bone repair following pulsed ultrasound therapy. Equine Practice, v.13, n.4, p.17-24, 1991.
LOW, J.; REED, A. Ultra-som terapêutico. In: Eletroterapia aplicada: princípios e prática. São Paulo: Manole, 2001. Cap.6, p.187-228.

MACHADO, C.M. Ultra-som. In: Eletroterapia prática. 2.ed. São Paulo: Pancast, 1991. 143p.

McILWRAITH, C.W. Doenças das articulações, tendões, ligamentos e estruturas relacionadas. In: ADAMS, O.R.; STASHAK, T.S. Claudicação em eqüinos. São Paulo: Roca, 1994. p.462-478.

MARTINES, M.U. et al. O efeito do ultra-som em reações químicas. Química Nova, v.23, n.2, p.251-256, 2000.

MAYR, E. et al. Ultrasound-an alternative heading method for nonunions? Archives Orthopaedic Trauma and Surgery, v.120, n.1-2, p.1-8, 2000.

MAXWELL, L. Therapeutics ultrasound: its eflects on the cellular and molecular mechanisms of inflammations and repair. In: _ Phisiotherapy. London: Churchill Livingstone, 1995. Cap.3, p.35-59.

MENEZES, D.F. et al. Aplicação de ultra-som terapêutico em lesão experimental aguda. Revista Brasileira de Fisioterapia, v.4, n.1, p.27-31, 1999.

MORTIMER, A.J.; DYSON, M. The effect of therapeutic ultrasound on calcium uptake in fibroblasts. Ultrasound in Medicine \& Biology, v.14, p.499-506, 1988.

NARUSE, H. et al. Anabolic response of mouse bone-marrow derived stromal cell clone to low-intensity pulsed ultrasound. Biochimical and Biophysical Research Communications, v.268, p.216-220, 2000.

OKUNO, E. et al. Física para ciências biológicas e biomédicas. São Paulo: Harba, 1986. 490p.

OLSSON, D.C. et al. Pulsed and continuous ultrasound stimulation in rats healing celiotomy. Ciencia Rural, v.36, n.3, p.865-872, 2006.

PAULA, J.L. Ultra-som terapêutico: considerações gerais. Fisioterapia em Movimento, v.VII, n.1, p. 9-16, 1994.

PARTRIDGE, C.J. Evaluation of ultrasound therapy devices. Physiotherapy, v.73, n.4, p.166-168, 1987.

PILLA, A.A. et al. Non-invasive low-intensity pulsed ultrasound accelerates bone healing in the rabbit. Journal Orthopaedic and Trauma, v.4, p.246-253, 1990.

RAWOOL, M.N. et al. Power doppler assesment of vascular changes during fracture treatment with low-intensity ultrasound. Journal of Ultrasound in Medicine, v.22, p.145-153, 2003.

RODRIGUES, E.M.; GUIMARÃES, C.S. Manual de recursos fisioterapêuticos. Rio de Janeiro. Revinter, 1998. 145p.

SAINI, N.S. et al. A preliminary study on the effect of ultrasound therapy on the healing of surgically severed Achilles tendons in five dogs. Journal of Veterinary Medicine, v.49, p.321328, 2002. 
SANTOS, V.L.C.G. Avanços tecnológicos no tratamento de feridas e algumas aplicações em domicílio. In: DUARTE, Y.A.O.; DIOGO, M.J.D. Atendimento domiciliar: um enfoque gerontológico. São Paulo: Atheneu, 2000. 306p.

SILVEIRA, S.D. O ultra-som terapêutico no processo cicatricial de tendões flexores digitais superficiais em cães. 2003. 74f. Dissertação (Mestrado em Cirurgia Experimental) - Universidade Federal de Santa Maria.

SOUZA, V.L. Efeitos do ultra-som de baixa intensidade sobre a consolidação óssea em fraturas de ossos longos (rádio, ulna, fêmur, tíbia e fíbula) em cães (Canis familiaris). 127f. 2003. Dissertação (Mestrado em Cirugia) Faculdade de Medicina Veterinária e Zootecnia, Universidade Federal de São Paulo.

SPEED, C.A. Therapeutic ultrasound in soft tissue lesions. Rheumatology, n.40, p.1331-1336, 2001.

STARKEY, C. Recursos terapêuticos em fisioterapia. 2.ed. São Paulo: Manole, 2001. 404p.

STASHAK, T.S. Selected factors that affect wound healing. In: Equine wound management. Philadelphia: Lea \& Febiger, 1991. Cap.2, p.19-34.

STEISS, J.E.; ADAMS, C.C. Effects of coat on rate of temperature increase in muscle during ultrasound treatment of dogs. American Journal of Veterinary Research, v.60, n.1, p.76-80, 1999

TAYLOR, A.R. et al. Therapeutic ultrasound. In: STEISS, J.E.; MCCAULEY, L. Canine rehabilitation \& physical therapy. St. Louis: Saunders, 2004. Cap.19, p.324-336.

TER HAAR, G. Basic physics of therapeutic ultrasound. Physiotherapy, v.64, n.4, p.100-103, 1978.
TER HAAR, G. Princípios eletrofísicos. In: KITCHEN, S.; BAZIN, S. Eletroterapia de Clayton. São Paulo: Manole, 1996. p.3-30.

TER HAAR, G. Therapeutic ultrasound. European Journal Ultrasound, Shannon, v.9, n.1, p.3-9, 1999.

VAEZI, S. et al. Hemostasis of punctured blood vessels using high-intensity focused ultrasound. Ultrasound Medicine \& Biology, v.24, n.6, p.903-910, 1998.

VAEZI, S. et al. Use of high-intensity focused ultrasound to control bleeding. Journal of Vascular Surgery, v.29, n.3, p.533-542, 1999

WARDEN, S.J. et al. Efficacy of low-intensity pulsed ultrasound in the prevention of osteoporosis following spinal cord injury. Bone, v.29, n.5, p.431-436, 2001a.

WILLIAMS, R.A. Ultrasound: biological effects and potential hazards. London, New York: Academic, 1983. 93p.

WITTE, M.B.; BARBUL, A. General principles of wound healing. Surgical Clinics of North America, v.77, p.509528, 1997.

YAMADA, B.F.A. Úlceras venosas. In: JORGE, S.S.; DANTAS S.R.P.E. Abordagem multiprofissional no tratamento de feridas. São Paulo: Atheneu, 2003. p.247-259.

YOUNG, S.T. The effect of therapeutic ultrasound on the biological mechanisms envolved in dermal repair. $174 \mathrm{f}$ 1988. Tese (Doutorado em Física) - University of London.

YOUNG, S. R.; DYSON, M. Effect of therapeutic ultrasound on the healing of fullthickness excise skin lesions. Ultrasonic, v.28, n.3, p.175-180, 1990

YOUNG, S.T. Terapia por ultra-som. In: KITCHEN, S.; BAZIN, S. Electroterapia de Clayton. São Paulo: Manole, 1996. Cap.15, p.235-258. 